\title{
Farmers' perceptions and adoption of new agricultural technology: evidence from analysis in Burkina Faso and Guinea, West Africa
}

\author{
Akinwumi A. Adesina ${ }^{\text {a, } *}$, Jojo Baidu-Forson ${ }^{\text {b }}$ \\ ${ }^{a}$ West Africa Rice Development Association, 01 BP 2551, Bouaké 01, Ivory Coast \\ ${ }^{\mathrm{b}}$ International Crops Research Institute for the Semi-Arid Tropics, Niamey, Niger
}

Accepted 14 May 1995

\begin{abstract}
Economists investigating consumer demand have accumulated considerable evidence showing that consumers generally have subjective preferences for characteristics of products and that their demand for products is significantly affected by their perceptions of the product's attributes. However, the role of farmers' preferences in adoption decisions have received very limited attention in adoption studies conducted by economists. This paper tests the hypothesis that farmers' perceptions of technology characteristics significantly affect their adoption decisions. The analysis, conducted with Tobit models of modern sorghum and rice varietal technologies in Burkina Faso and Guinea, respectively, strongly supports this hypothesis. Our results provide a strong case for future adoption studies to expand the range of variables used away from the broad socio-economic, demographic and institutional factors to include farmers' subjective perceptions of the characteristics of new agricultural technologies.
\end{abstract}

\section{Introduction}

The importance of commodity-attribute perceptions has long been of interest to social scientists investigating agricultural technology adoption decisions. Indeed, anthropologists and sociologists have played a lead role in this area and have argued, using qualitative methods, that farmers' subjective assessments of agricultural technologies influence adoption behavior (Kivlin and Fliegel, 1966, 1967; Nowak, 1992). Economists have generally lagged behind in investigating this issue. However, since most earlier works on tech-

\footnotetext{
* Corresponding author.
}

nology adoption by economists (O’Mara, 1980) did not have access to direct observations on farmers' perceptions, it was not possible to directly and quantitatively test the hypothesis that perceptions of technology attributes influence adoption decisions. Instead, variables which affect farmers' access to information, and hence their perception formation (e.g. extension, education, media exposure, etc.), are typically used in economic models of the determinants of adoption decisions (Feder et al., 1985; Shakya and Flinn, 1985; Kebede et al., 1990; Polson and Spencer, 1991; Strauss et al., 1991).

Economists investigating consumer demand have, however, accumulated considerable evidence showing that consumers generally have 
subjective preferences for characteristics of products and that their demand for products is significantly affected by their perceptions of the product's attributes (Jones, 1989; Lin and Milon, 1993). For example, using a double-hurdle model, Lin and Milon (1993) found that commodity attributes and consumers' safety perceptions were significant in explaining decisions to consume and the frequency of consumption of shellfish in the USA. Similarly, Jones (1989) found, using Cragg's double-hurdle framework, that consumers' subjective perceptions influenced cigarette smoking decisions. Economists investigating the adoption of new agricultural technology have lagged behind in investigating how farmers' (the consumers of agricultural technologies) subjective perceptions of technology characteristics affect their adoption decisions. In extensive reviews of adoption studies in developing countries (Feder et al., 1985; Feder and Umali, 1993), no study was found to have analyzed the direct effects of farmers' subjective assessments of agricultural technology characteristics on adoption decisions. In their recent study, Adesina and Zinnah (1993a) found that farmers' perceptions of the characteristics of modern rice varieties significantly affected adoption decisions in Sierra Leone. The paucity of empirical economic studies on this issue justifies further investigation. The objective of this paper is to determine the effects of farmers' perceptions of agricultural technology characteristics on adoption decisions, using comparative analysis of two technologies in West Africa (i.e. improved sorghum varieties in Burkina Faso, and improved mangrove rice varieties in Guinea).

A historical background of the development of the new agricultural technologies examined in this paper is briefly discussed below. Sorghum improvement activities in West Africa have been a major focus of research conducted by the International Crops Research Institute for the SemiArid Tropics (ICRISAT) which has the global mandate for sorghum improvement. ICRISAT's sorghum improvement work started in Burkina Faso in 1975/1976. Most of the initial work was on the screening of introduced and local germplasm. Breeding started much later. Among the principal breeding objectives were: good and stable yield performance under both traditional and improved soil fertility management conditions and good grain quality, especially for making 'tô', a very popular local porridge across the Sahel (ICRISAT, 1980-1983). As striga-a parasitic weed-has been a major problem facing sorghum (and, indeed, cereal) farmers in West Africa, a complementary program on screening for striga-resistant varieties formed a major part of ICRISAT's research program (Ramaiah, 1991). A number of improved varieties was developed and tested in on-farm tests in Burkina Faso, e.g. ICSV 1049 BF, ICSV 1002 BF, etc. While farm tests have been conducted on these varieties in eastern Burkina Faso (Matlon, 1985; Wildschut and Ouattara, 1987), little is known about the factors affecting the adoption decisions of farmers.

Research on the development of mangrove rice in West Africa is carried out by the West Africa Rice Development Association (WARDA). Starting in 1976, WARDA maintained a regional rice improvement program in Sierra Leone, targeting the approximately 200000 ha of mangrove swamps cultivated to rice in West Africa. The mangrove rice ecologies, located on tidal estuaries that are near the ocean, are important rice growing environments for six countries in West Africa: Guinea, Guinea Bissau, Senegal, Gambia, Sierra Leone and Nigeria. In Guinea, about 64000 ha of mangrove rice area is under cultivation, representing $12 \%$ and $18 \%$ of national rice area and rice production, respectively. Seeds of the modern varieties (e.g. ROK-5, ROK-10, Kuatik Kundur) were recently diffused to neighboring Guinea (Zinnah et al., 1993). One of the varieties, ROK-5, has been increasingly adopted. In the Coyah region (the country's major mangrove swamp rice growing zone), it was estimated that the percentage of farmers cultivating ROK-5 increased from $1 \%$ in 1989 to $15 \%$ in 1990 (Adesina and Zinnah, 1993b). On-farm tests conducted from 1982 to 1985 showed that these modern mangrove rice varieties consistently outyielded the best local varieties by more than $30 \%$ (Agyen-Sampong, 1990). Little is known, however, about the determinants of farmers' adoption of these varieties. 
The rest of the paper is divided into three sections. Section 2 describes the conceptual and empirical models, while Section 3 discusses the empirical results. Section 4 presents conclusions and implications of the results for adoption studies.

\section{Methods}

A given agricultural technology embodies a number of important characteristics that may influence adoption decisions. The observed adoption choice on an agricultural technology (e.g. modern crop varieties) is hypothesized to be the end result of a complex set of inter-technology preference comparisons made by farmers. Let the perceived benefits derived from growing a modern variety and the local variety be represented by $b(m)$ and $b(l)$, respectively. Let the $i$ th farmer's perceptions of the varietal-specific characteristics of the modern and local rice varieties be given by $p_{i \mathrm{~m}}$ and $p_{i 1}$, respectively. Let the other socio-economic and demographic characteristics of farm households affecting the adoption decision be denoted as $c_{i}$. For simplicity, let these relations be represented as $b_{\mathrm{m} i}=q\left(p_{i \mathrm{~m}}\right.$, $\left.p_{i 1} ; c_{i}\right)$ and $b_{1 i}=w\left(p_{i \mathrm{~m}}, p_{i 1} ; c_{i}\right)$, respectively. To model this effect of perceptions of technology attributes on adoption decisions a Tobit model is used. This is represented below using an index function approach

$$
\begin{aligned}
& V_{i}^{*}=\beta^{T} X_{i}+\epsilon_{i} \\
& V_{i}=0 \text { if } V_{i}^{*} \leqslant 0 \\
& V_{i}=V_{i}^{*} \text { if } V_{i}^{*}>0
\end{aligned}
$$

where $V_{i}$, a limited dependent variable, is the perceived benefit of adoption of the modern variety; $V_{i}{ }^{*}$ is an underlying latent variable that indexes adoption; $X$ is the vector of socio-economic and demographic characteristics of the farm household, and the technology perceptions of the farmer; $\beta^{\mathrm{T}}$ is a vector of parameters to be estimated; and $\epsilon_{i}$ is an error term. When the inter-varietal attribute preference comparisons are such that $b_{\mathrm{m} i}-b_{1 i}>0$ (i.e. $V_{i}^{*}>0$ ) the farmer is observed to adopt the modern variety $\left(V_{i}=V_{i}^{*}\right.$
$>0$ ). Otherwise, if $b_{\mathrm{m} i}-b_{1 i} \leqslant 0$ (or $V_{i}{ }^{*} \leqslant 0$ ) no adoption is observed (i.e. $V_{i}=0$ ). The model permits the investigation of the decision of whether or not to adopt and the conditional level of use of the technology if the initial adoption decision was made. The Tobit model also has an advantage in that its coefficients can be further disaggregated to determine the effect of a change in the $i$ th variable on changes in the probability of adopting the modern variety and the expected use intensity of the variety. Following McDonald and Moffitt (1980), it can be shown that

$E\left(V_{i}\right)=\Phi(z) E\left(v_{i}^{*}\right)$

where $E\left(v_{i}^{*}\right)$ is the expected value of $V_{i}$ for those farmers that have already made the adoption decision, and $\Phi$ is the cumulative normal distribution function at $z$, where $z$ is $X \beta / \sigma$.

Differentiating with respect to any element of $X$ gives

$$
\begin{aligned}
\partial E\left(V_{i}\right) / \partial X_{i}= & \Phi(z)\left\{\partial E\left(v_{i}^{*}\right) / \partial X_{i}\right\} \\
& +E\left(v_{i}^{*}\right)\left\{\partial \Phi(z) / \partial X_{i}\right\}
\end{aligned}
$$

Multiplying through by $X_{i} / E\left(V_{i}\right)$, the relation can be converted into elasticity forms

$$
\begin{aligned}
\left\{\partial E\left(V_{i}\right) / \partial X_{i}\right\} X_{i} / E\left(V_{i}\right) \\
=\Phi(z)\left\{\partial E\left(v_{i}^{*}\right) / \partial X_{i}\right\} X_{i} / E\left(V_{i}\right) \\
\quad+E\left(v_{i}^{*}\right)\left\{\partial \Phi(z) / \partial X_{i}\right\} X_{i} / E\left(V_{i}\right)
\end{aligned}
$$

Re-arranging this using Eq. (2.1) gives

$$
\begin{aligned}
&\left\{\partial E\left(V_{i}\right) / \partial X_{i}\right\} X_{i} / E\left(V_{i}\right) \\
&=\left\{\partial E\left(v_{i}^{*}\right) / \partial X_{i}\right\} X_{i} / E\left(v_{i}^{*}\right) \\
&+\left\{\partial \Phi(z) / \partial X_{i}\right\} X_{i} / \Phi(z)
\end{aligned}
$$

The total elasticity consists of two effects: (1) the change in the probability of the expected level of use intensity of the modern varieties for those farmers that are already adopters, and (2) the change in the elasticity of the probability of being an adopter.

The empirical models are discussed below. For the sorghum model, the dependent variable is the share of the total sorghum area that is cultivated in improved varieties (ISSHARE), while the dependent variables are, respectively, farmers' subjective assessments of: yield performance 
(YIELD), the quality of the local porridge (tô) that farmers make from sorghum (TO), performance under poor soil conditions (SOIL), tolerance to striga weed infestation (STRIGA), and drought tolerance (DROUGHT). It is hypothesized that these factors are positively related to adoption decisions. In addition to these factors, the following socio-economic and demographic variables were included as explanatory variables in the model: the age of the farmer (AGE), whether or not the farmer was a village head and the number of years since becoming village head (HEAD), participation of the farmer in on-farm tests of the improved sorghum varieties (TEST), number of times the farmer was visited by extension agents in the survey year (VISIT), and the number of times the farmer participated in extension related workshop training activities (WKSHOP). It is hypothesized that TEST and AGE are positively related to adoption decisions. Testing the varieties in on-farm tests can be expected to influence adoption decisions. The expected sign on $A G E$ is an empirical question: it may be that older farmers have more experience in cultivation and are better able to assess the characteristics of modern technology than younger farmers. However, it could also be that older farmers are more risk averse than younger farmers and have a lesser likelihood of adopting new technologies. There is no agreement in the adoption literature on this as the direction of the effect is generally location or technology specific (Kebede et al., 1990; Polson and Spencer, 1991). Based on the innovation-diffusion literature, it is hypothesized that extension visits (VISIT) and participation in workshops (WKSHOP) are positively related to adoption by exposing farmers to 'new information'.

For the Guinea model, the dependent variable is the share of the total mangrove swamp rice area that is cultivated in improved varieties (RSHARE). Two classes of explanatory variables are included in the model. The first set (i.e. technology perceptions) are farmers' subjective assessments of the following characteristics of the rice varieties: yield performance (YIELD), ease of cooking (COOK), tillering capacity (TILLER), and ease of threshing (THRESH). The inclusion of these variables allows us to compare our results with those obtained earlier by Adesina and Zinnah (1993a) in Sierra Leone. Based on these results, it is hypothesized that these factors are positively related to adoption decisions in Guinea. Ease of cooking is likely to be important to these rice farmers because of the scarcity of fuel-wood for preparing food in the mangrove areas. Farmers are obliged to travel several kilometers to search for fuel-wood. Ease of cooking of rice varieties is linked to the gelatinization temperature of the rice. Varieties with high gelatinization temperature take longer periods to cook (Unnevehr, 1986). This increases the demand for fuel-wood, a very scarce input in the mangrove environments where most of the mangrove trees have been cut down by farmers. Thus, farmers may tend to adopt varieties that puts less pressure on the scarce fuel-wood supply. Tillering capacity is also very critical in the mangrove ecology because of the high damage to young rice seedlings from crabs. Varieties that have the capacity to produce tillers fast, and which reproduce secondary tillers following initial crab damage, are likely to be adopted by farmers. The high labor demands for manual threshing in this farming system, where labor is the most limiting factor, may create incentives for farmers to adopt varieties that are easier to thresh. Finally, better yield performance over local varieties is expected to positively affect adoption decisions. The other socio-economic and demographic factors of the farmer in the model are: age of the farmer (AGE), the farm size (FSIZE), participation in on-farm tests (TEST), visit by extension agents (VISIT), and years of experience in mangrove rice farming (EXP). The expected signs of these variables follow that discussed above for the Burkina Faso case. In addition, it is expected that EXP is positively related to adoption as more experienced farmers may be able to better assess new technologies.

In each model, the subjective perception variables were defined as dichotomous variables that take on the value of 1 if the farmer considered that the new agricultural technology is better than the local technology for a given technology attribute, and a value of 0 , otherwise. The empiri- 
cal models were estimated using an iterative maximum likelihood algorithm (White, 1978) in order to obtain asymptotically efficient parameter estimates. The data for the Burkina Faso study were collected in 1989/1990 from a sample of 57 farmers in the east central region. Data for the Guinea study were collected in 1990-1991 from a sample of 110 farmers in the Coyah region.

\section{Results}

The results for the sorghum model in Burkina Faso are given in Table 1. The analyses show that farmers' perceptions of four varietal technology characteristics were positively related to the probability of adoption and intensity of cultiva- tion of the improved sorghum varieties. Significant (at the 5\% level) were quality for making sorghum paste (TO) and performance under poor soil conditions (SOIL). The coefficient on yield performance (YIELD) is barely significant at $10 \%$. Farmers' assessment of the relative tolerance of the improved varieties to striga (STRIGA), though positively related to adoption decisions, was not significant. The negative sign on the drought tolerance variable (DROUGHT) is unexpected and may be due to negative correlation between this variable and other varietal characteristics not included in the model. Two farmer characteristics were significant in explaining adoption decisions: the age of the farmer (AGE) and farmers' participation in on-farm tests (TEST). The latter variable was the most highly

Table 1

Estimated tobit model for factors affecting the adoption of modern sorghum varieties in Burkina Faso, 1989/1990

\begin{tabular}{|c|c|c|c|c|c|}
\hline & \multirow{2}{*}{$\begin{array}{l}\text { Normalized } \\
\text { coefficient }\end{array}$} & \multirow{2}{*}{$\begin{array}{l}\text { Standard } \\
\text { error }\end{array}$} & \multirow[t]{2}{*}{$T$-ratio } & \multicolumn{2}{|c|}{ Elasticity of } \\
\hline & & & & $\begin{array}{l}\text { Adoption } \\
\text { index }\end{array}$ & $\begin{array}{l}\text { Expected level } \\
\text { of use intensity }\end{array}$ \\
\hline Intercept & -5.8974 & 1.7202 & $-3.4283^{* * *}$ & & \\
\hline $\begin{array}{l}\text { Perception of yield } \\
\text { (YIELD) }\end{array}$ & 0.9635 & 0.5820 & $1.6555^{*}$ & 1.2401 & 0.5242 \\
\hline $\begin{array}{l}\text { Perception of quality of } \\
\text { local sorghum porridge (TO) }\end{array}$ & 1.8214 & 0.7268 & $2.5058^{* *}$ & 0.8930 & 0.3775 \\
\hline $\begin{array}{l}\text { Perception of adaptability } \\
\text { to poor soils (SOIL) }\end{array}$ & 1.5951 & 0.7103 & $2.2456^{* *}$ & 2.9328 & 1.2397 \\
\hline $\begin{array}{l}\text { Perception of tolerance } \\
\text { to striga weed (STRIGA) }\end{array}$ & 0.2679 & 0.4750 & 0.5642 & 0.6405 & 0.2707 \\
\hline $\begin{array}{l}\text { Perception of drought } \\
\text { tolerance (DROUGHT) }\end{array}$ & -2.1313 & 0.7477 & $-2.8506^{* *}$ & -2.8681 & -1.2123 \\
\hline Age of the farmer (AGE) & 0.0613 & 0.0325 & $1.8850^{*}$ & 20.0953 & 8.4941 \\
\hline Village head (HEAD) & -0.0326 & 0.0299 & -1.0875 & -4.1800 & -1.7669 \\
\hline $\begin{array}{l}\text { Participation in } \\
\text { on-farm tests (TEST) }\end{array}$ & 1.2103 & 0.2578 & $4.6944^{* * *}$ & 10.4590 & 4.4209 \\
\hline $\begin{array}{l}\text { Number of times farmer } \\
\text { was visited by extension } \\
\text { agents (VISIT) }\end{array}$ & 0.0064 & 0.0753 & 0.0855 & 0.0288 & 0.0122 \\
\hline $\begin{array}{l}\text { Number of times farmer } \\
\text { participated in extension- } \\
\text { related workshops } \\
\text { (WKSHOP) }\end{array}$ & -0.3342 & 0.1376 & $-2.4281^{* *}$ & -2.8681 & -1.2123 \\
\hline
\end{tabular}

The parameters were evaluated using one-tailed $t$-tests. Asterisks indicate significance at: ${ }^{* * *} 1 \%{ }^{* *} 5 \%$; ${ }^{*} 10 \%$.Dependent variable, ISSHARE.

Log-likelihood function, 9.8697.

Mean square error, $0.8218 \mathrm{E}-03$.

Mean error, 0.9482E-03.

Squared correlation between observed and expected values, 0.5183 . 
significant of all the explanatory variables. This is not unexpected, because extensive sorghum onfarm trials were carried out in the survey area. The negative sign on WKSHOP is unexpected and may be explained by the possibility that the workshops farmers attended were not specifically on sorghum. Some authors have also argued that what is important is not this contact with extension but how farmers assess the relevance of the issues discussed at such farmer workshops for their actual production decisions (Zinnah et al., 1993).

These results have implications for sorghum technology improvement research in West Africa. First, it shows that yield performance of sorghum technologies needs to be evaluated by farmers under their own soil conditions. The results showed that varieties that farmers judge as having superior yield performance over local varieties under on-farm soil fertility conditions tend to be those that are adopted. Secondly, the analyses show that sorghum technology development efforts should not only concentrate on agronomic characteristics. The strong significance of the food quality variable indicates that farmers are concerned about non-agronomic characteristics. As sorghum is principally used in West Africa for making tô, research efforts need to be focused on screening for lines with appropriate good grain and food quality for making this local porridge. One way to ensure this is to have farmers, especially women, assess the food quality of all sorghum varieties that are proposed for on-farm testing in West Africa.

Results for the Guinea model are given in Table 2. The results show that all the four technology-characteristic perceptions were strongly significant in explaining farmers' adoption decisions. These results are very similar to those obtained by Adesina and Zinnah (1993a) in Sierra

Table 2

Estimated tobit model for factors affecting the adoption of modern mangrove rice varieties in Guinea, 1990/1991

\begin{tabular}{|c|c|c|c|c|c|}
\hline & \multirow{2}{*}{$\begin{array}{l}\text { Normalized } \\
\text { coefficient }\end{array}$} & \multirow{2}{*}{$\begin{array}{l}\text { Standard } \\
\text { error }\end{array}$} & \multirow[t]{2}{*}{$T$-ratio } & \multicolumn{2}{|c|}{ Elasticity of } \\
\hline & & & & $\begin{array}{l}\text { Adoption } \\
\text { index }\end{array}$ & $\begin{array}{l}\text { Expected level } \\
\text { of use intensity }\end{array}$ \\
\hline Intercept & -0.9534 & 0.5395 & $-1.7671^{*}$ & & \\
\hline $\begin{array}{l}\text { Perception of yield } \\
\text { (YIELD) }\end{array}$ & 0.7610 & 0.2875 & $2.6469^{* * *}$ & 0.2676 & 0.2491 \\
\hline $\begin{array}{l}\text { Perception of ease of } \\
\text { cooking (COOK) }\end{array}$ & 0.7782 & 0.3146 & $2.4735^{* *}$ & 0.3741 & 0.3482 \\
\hline $\begin{array}{l}\text { Perception of tillering } \\
\text { capacity (TILLER) }\end{array}$ & 1.0347 & 0.2934 & $3.526^{* * *}$ & 0.3805 & 0.3542 \\
\hline $\begin{array}{l}\text { Perception of ease of } \\
\text { threshing (THRESH) }\end{array}$ & 0.6621 & 0.2838 & $2.3324 * *$ & 0.2542 & 0.2366 \\
\hline Age of the farmer (AGE) & -0.0009 & 0.0116 & -0.0771 & -0.0604 & -0.0563 \\
\hline Farm size (FSIZE) & -0.1092 & 0.1166 & -0.9369 & -0.2171 & -0.2021 \\
\hline $\begin{array}{l}\text { Participation in on-farm } \\
\text { tests (ON-FARM) }\end{array}$ & 0.2221 & 0.3109 & 0.7142 & 0.0382 & 0.356 \\
\hline $\begin{array}{l}\text { Number of times farmer } \\
\text { was visited by extension } \\
\text { agents (VISIT) }\end{array}$ & 0.0175 & 0.0600 & 0.2926 & 0.0061 & 0.0056 \\
\hline $\begin{array}{l}\text { Years of experience } \\
\text { in rice farming } \\
\text { (EXP) }\end{array}$ & 0.0115 & 0.0110 & 1.0399 & 0.4141 & 0.3854 \\
\hline
\end{tabular}

The parameters were evaluated using one-tailed $t$-tests. Asterisks indicate significant at: ${ }^{* * *} 1 \%{ }^{* *} 5 \%$; ${ }^{*} 10 \%$.

Dependent variable, RSHARE.

Log-likelihood function, -24.985 .

Mean square error, 0.3353E-01.

Mean error, $-0.1382 \mathrm{E}-01$.

Squared correlation between observed and expected values, 0.502 . 
Leone. It is also important to note that a nonagronomic trait (ease of cooking) significantly affected farmers' adoption decisions. When taken together with the results for sorghum in Burkina Faso, it is clear that farmers consider factors related to food quality as very critical in adoption decisions. This suggests that the conventional approach of focusing technology development mostly on enhanced agronomic characteristics needs to be changed to also significantly encompass food quality characteristics.

The Guinea results show that none of the so-called 'contact' variables were significant in influencing adoption decisions. The lack of significance of the extension variable supports the finding by other researchers that researcher-extension-farmer linkages are extremely weak in Guinea and that most of the mangrove varieties currently grown by farmers were obtained via farmer-farmer contacts (Zinnah et al., 1993). Comparative analyses of the results in Guinea and Burkina Faso with the results earlier reported for Sierra Leone by Adesina and Zinnah (1993a) show some important patterns in the role of extension and other farmer contact variables in influencing farmers' adoption decisions. In the case of mangrove rice varieties in Guinea and Sierra Leone, extension had very little to do with technology diffusion: this occurred mainly through farmers self-experimentation, evaluation, exchange and transfer. In the case of sorghum in Burkina Faso, extensive on-farm testing of the varieties in a number of test-villages appears to have affected adoption decisions. This suggests that extension workers do not influence technology transfer in all cases. Farmers are also important as sources of technology information and agents of technology transfer. When farmers assess the characteristics of new technologies and find them to match their preferences, they often give the technologies to other farmers to test and evaluate thereby setting into motion an endogenous process of technology diffusion.

\section{Conclusions}

The analyses in this paper showed that farmers' subjective preferences for characteristics of new agricultural technologies are very important determinants of adoption behavior. The results are robust in that this conclusion is the same for the two different technologies examined in Burkina Faso and Guinea. The results agree with the evidence provided by studies of consumer demand showing that consumers critically evaluate characteristics of a product and that demand is affected by consumers' subjective assessments of product attributes (Jones, 1989; Lin and Milon, 1993). Farmers are consumers of the products of agricultural research and their subjective preferences for characteristics of new agricultural technologies affect their adoption decisions.

Our results, which lend support to the earlier finding of Adesina and Zinnah (1993a), call for more theoretical and empirical studies to examine the effects of farmers' subjective preferences of technology characteristics on adoption decisions. An advantage of the approach we have used is that it is possible to identify the key characteristics of technologies that need to be targeted for improvement if adoption is to be achieved. Future studies in this area should overcome a limitation of the current analyses: the data we had did not permit us to measure the intensity of the perceptions, as was done by Lin and Milon (1993) in their study of consumer demand in the USA. We suggest that future studies collect data that measure not only the dichotomous comparison of preferences for technology attributes but also the intensity of those preferences. Another possible limitation of the current analyses is the possibility of estimation bias from simultaneity if the perception variables and the other 'contact' variables (i.e. contact with extension, participation in on-farm tests etc.) are endogenous. It was not possible for us to examine this issue owing to the evidently formidable econometric problems associated with estimating simultaneous equation systems with dummy or other limited dependent variables. Also important is the need for studies to examine non-adoption of new agricultural technologies and how farmers' subjective preferences for technology attributes play a role (Yapa and Mayfield, 1978; Nowak, 1992). Nonetheless, our results provide a strong case for future adoption studies to expand 
the range of variables used away from the broad socio-economic, demographic and institutional factors (Feder et al., 1985; Feder and Umali, 1993), to include farmers' subjective perceptions of the characteristics of new agricultural technologies.

\section{Acknowledgments}

The authors are grateful to two anonymous reviewers of this journal for providing us with very helpful comments. We are also grateful to Peter Matlon, Kofi Debrah and Timothy $O$. Williams for helpful comments and discussions on earlier versions of the paper. Responsibility for errors remains with us. Part of this study was conducted while the first author was a Rockefeller Social Science Research Fellow and Assistant Principal Economist at the International Crops Research Institute for the Semi-Arid Tropics, while based at the West Africa Sorghum Improvement Program in Mali. The funding of The Rockefeller Foundation for his work is gratefully acknowledged. The assistance provided by our colleagues at INERA and CRPA/Koupela in Burkina Faso throughout the field work is gratefully acknowledged.

\section{References}

Adesina, A.A. and Zinnah, M.M., 1993a. Technology characteristics, farmer perceptions and adoption decisions: a tobit model application in Sierra Leone. Agric. Econ., 9: 297-311.

Adesina, A.A. and Zinnah, M.M., 1993b. Impact of modern mangrove swamp rice varieties in Sierra Leone and Guinea. Int. Rice Res. Notes, 18: 36.

Agyen-Sampong, M., 1990. History of rice research in Rokupr: Evaluation and overview of WARDA's mangrove rice program, and relationship to national program. West Africa Rice Development Association, Rokupr, Sierra Leone.

Feder, G. and Umali, D., 1993. The adoption of agricultural innovations. A review. Technol. Forecast. Soc. Change, 43: 215-239.

Feder, G., Just, R.E. and Zilberman, D., 1985. Adoption of agricultural innovations in developing countries: a survey. Econ. Dev. Cult. Change, 33: 255-297.

International Crops Research Institute for the Semi-Arid
Tropics, 1980. Annual Report Cooperative Program/ Upper Volta. ICRISAT, Upper Volta.

International Crops Research Institute for the Semi-Arid Tropics, 1981. Annual Report Cooperative Program/ Upper Volta. ICRISAT, Upper Volta.

International Crops Research Institute for the Semi-Arid Tropics, 1982. Annual Report Cooperative Program/ Upper Volta. ICRISAT, Upper Volta.

International Crops Research Institute for the Semi-Arid Tropics, 1983. Annual Report Cooperative Program/ Upper Volta. ICRISAT, Upper Volta.

Jones, A.M., 1989. A double-hurdle model of cigarette consumption. J. Appl. Econometrics, 4: 23-29.

Kebede, Y., Gunjal, K. and Coffin, G., 1990. Adoption of new technologies in Ethiopian agriculture: the case of Teguelet-Bulga District, Shoa Province. Agric. Econ., 4: 27-43.

Kivlin, J.E. and Fliegel, F.C., 1966. Attributes of innovations as factors in diffusion. Am. J. Sociol., 72: 235-248.

Kivlin, J.E. and Fliegel, F.C., 1967. Differential perceptions of innovations and rate of adoption. Rural Sociol., 32: 78-91.

Lin, C.T.J. and Milon, J.W., 1993. Attribute and safety perceptions in a double-hurdle model of shellfish consumption. Am. J. Agric. Econ., 75: 724-729.

Matlon, P.J., 1985. A critical review of objectives, methods, and progress to date in sorghum and millet improvement: a case study of ICRISAT/Burkina Faso. In: H.W. Ohm and J.G. Nagy (Editors), Appropriate Technologies for Farmers in Semi-Arid West Africa. Purdue University, Lafayette, IN, pp. 154-179.

McDonald, J.F. and Moffitt, R.A., 1980. The uses of Tobit analysis. Rev. Econ. Stat., 62: 318-321.

Nowak, P., 1992. Why farmers adopt production technology. J. Soil Water Conserv., 47: 14-16.

O'Mara, G., 1980. The micro-economics of technique adoption by small-holding Mexican farmers. World Bank Development Research Center, Washington DC.

Polson, R.A. and Spencer, D.S.C., 1991. The technology adoption process in subsistence agriculture: The case of cassava in South Western Nigeria. Agric. Syst., 36: 65-77.

Ramaiah, K.V., 1991. Breeding for striga resistance in sorghum and millet. In: S.K. Kim (Editor), Combating Striga in Africa. International Institute of Tropical Agriculture, Ibadan, Nigeria, pp. 75-80.

Shakya, P.B. and Flinn, J.C., 1985. Adoption of modern varieties and fertilizer use on rice in the eastern Tarai of Nepal. J. Agric. Econ., 36: 409-419.

Strauss, J., Babosa, M., Teixeira, S., Thomas, D. and Gomes, R., 1991. Role of education in adoption of technology: a study of upland rice and soybean farmers in central-west Brazil. Agric. Econ., 5: 341-359.

Unnevehr, L.J., 1986. Consumer demand for rice grain quality and returns to research for quality improvement in southeast Asia. Am. J. Agric. Econ., 68: 634-641.

White, K.J., 1978. SHAZAM-A general computer program for econometric methods. Econometrica, 46: 239-240.

Wildschut, J. and Ouattara, A., 1987. Rapport Technique. 
Resultats de la campagne 1987. O.R.D. du Centre-Est, Burkina Faso.

Yapa, L.S. and Mayfield, R.C., 1978. Non-adoption of agricultural innovations: evidence from discriminant analysis. Econ. Geogr., 54: 145-156.
Zinnah, M.M., Compton, J.L. and Adesina, A.A., 1993. Research-extension-farmer linkages within the context of the generation, transfer and adoption of improved mangrove swamp rice technology in West Africa. Q. J. Int. Agric., 32: 201-211. 